\title{
Voltage minimization control of vector controlled interior permanent magnet motor
}

\author{
THAKUR SUMEET SINGH*D and AMIT KUMAR JAIN
}

Department of Electrical Engineering, Indian Institute of Technology Delhi, New Delhi 110016, India

e-mail: sumeet.nitw@gmail.com

MS received 14 July 2017; revised 11 March 2018; accepted 21 July 2018; published online 8 January 2019

\begin{abstract}
Maximum Torque Per Voltage trajectory has been utilized only during field weakening operation of Interior Permanent Magnet (IPM) motor. In this paper, the voltage minimization control from zero-speed is proposed. Voltage minimization results in maximum torque per voltage control of IPM motor. The control implementation is also simple in comparison to current minimization, as the operation is always along the current-limit locus irrespective of operation in field-weakening. Voltage minimization technique minimizes the core losses whereas current minimization would minimize the copper losses. The mathematical model of IPM motor following voltage minimization is derived and the solution to the $4^{\text {th }}$ order quartic equations is obtained using Ferrari's method. The solution obtained is utilized to develop a look-up table for vector control of IPM motor. A comparative analysis of voltage minimization and current minimization is established which is supported by simulation results and demonstrated by detailed experimental results.
\end{abstract}

Keywords. Interior permanent magnet; voltage minimization; current minimization; core loss minimization; copper loss minimization; maximum torque per voltage; field weakening; vector control.

\section{Introduction}

The demand for efficient high-speed motors for application such as electric vehicles and wind energy systems led to accelerated growth in the permanent magnet drives. In this regard, Interior Permanent Magnet motors are in great demand. In comparison to the Surface Mounted Permanent Magnet (SMPM) motors, IPM motors have higher power density and facilitate deep field weakening. Therefore, IPM motors are ideal for high efficiency and high-speed drives. Wide literature is available on IPM motors. Controls optimizing torque-current ratio and overall losses are widely followed. Jahns et al [1] demonstrated the Maximum Torque Per Ampere (MTPA) control of IPM control. The MTPA relation is normalized to make it parameter independent. Jahns [2] also demonstrated the flux-weakening operation of IPM motors. Morimoto et al [3] proposed high-performance current regulator for the wide-speed operation of IPM motors. Nguyen et al [4] proposed energy efficient operation of IPM motors by use of online-parameter identification based control. Alfio et al [5] demonstrated a novel scalar energy-saving control for industrial IPM drives. Sung-Yoon et al [6] proposed online-computation based current minimizing torque control of IPM. The quartic expressions of IPM motor under current minimization are solved online using Ferrari's method to

*For correspondence improve accuracy in comparison to Look Up Table (LUT) based control approach. Bon-Ho et al [7] proposed fieldweakening technique for high saliency IPM motors. A 2DLUT is utilized for the control implementation. Bolognani et al [8] proposed a novel approach for real-time tracking of MTPA, based on AC current injection.

Wide literature is also available on Direct Torque Control (DTC) [9] of IPM motors. Zhong et al [10] presents a detailed analysis of DTC for IPM motors. Rahman et al [11] present field weakening of IPM motors. Lixing et al [12] successfully demonstrated low ripple fixed frequency DTC for IPM motors. Haque et al [13] present initial position estimation by use of high-frequency signal injection. Literature on constant frequency based DTC control of drives is given in [14-19]. Tasuki et al [20, 21] demonstrated the MTPA control of direct torque controlled IPM motors in stator flux synchronous frame. Sensorless algorithms for IPM motors have also been well established. Ogasawara et al [22] demonstrated the position estimation utilizing the magnetic saliency of IPM motors. Lin et al [23] presents sensorless IPM motor drive over wide speed range. Chen et al [24] demonstrated the implementation of high-performance sensorless IPM motor. Literature on sensorless control is available in [25-32].

Ekanayake et al [32] suggested deep flux weakening operation of segmented IPM motor by utilizing the MTPV trajectory. Lin et al [33] presented infinite speed drives by utilizing MTPV trajectory in the flux- 
weakening region. Pellegrino et al [34] demonstrated the direct-flux vector control of IPM motors in MTPV speed range. In the previously established works, the Maximum Torque Per Voltage (MTPV) is utilized only in deep-flux weakening region. The trajectory MTPV i.e., voltage minimization per torque, has not been utilized from zerospeed. This paper proposes voltage minimization control technique of IPM motor starting from no-load and zero operating speed. Voltage minimization optimizes the torque developed per voltage and the core losses of the IPM motor. For the chosen IPM motor ["Appendix"], the MTPV trajectory lies outside of the current limit locus, thus cannot be utilized for control. The current limit locus itself becomes the operation trajectory for voltage minimization control, since it is the closest operating point to MTPV, within the motor operation limits. The current minimization [6] control is complicated especially for operation in field-weakening, as the trajectory of operation depends on operating speed, DC-link voltage, the torque required and current limit.

Majority of the low speed machines have higher copper losses as compared to the core losses. Although, in the case of high-speed low-current machines, especially those with low torque-high speed operation, the core losses would dominate chiefly at elevated speed operation. Some of the spindle based applications, a common example being the drilling machines used buy a dentist is a good example for high core loss to copper loss ratio. Such machines if operated along MTPV instead of MTPA would produce better efficiency. The voltage minimization is quite simple in implementation as the operation trajectory is always along the current limit locus irrespective of the onset of field weakening. This is due to the fact that the MTPV lies outside of current limit locus. Thus, this paper presents a voltage minimization from zero-start for core loss reduction. Although, a combination of core and copper loss techniques can be used as per the application requirements.

The mathematical model for IPM motor operation following voltage minimization is developed and the 4th order quartic equation involved is solved using Ferrari's method of quartic. The solution is utilized to develop a LUT for vector control of IPM drive. The proposed voltage minimization control is supported by detailed simulation and experimental observations. Also, comparison is made with current minimization technique. The paper is organized as follows: The basic mathematical model of IPM motor is given in section 2. The operation trajectories of IPM motor are given in section 3. The voltage minimization technique is explained in section 4, and the solution to the quartic equation is also given. Section 5 briefly explains the control algorithm. The proposed voltage minimization control technique is supported by simulation results in section 6 and demonstrated experimentally in section 7 . The concluding remarks are provided in section 8 .

\section{Mathematical model of IPM motor}

A mathematical model of the motor is necessary to understand its operation. The IPM motor can be expressed using the following set of differential equations [3]:

$$
\begin{gathered}
v_{q d s}=r_{s} i_{q d s}+\omega_{e} \lambda_{d q s}+p \lambda_{q d s} \\
\left(\lambda_{d q s}\right)^{T}=\left[\begin{array}{ll}
\lambda_{d s} & -\lambda_{q s}
\end{array}\right] \\
\lambda_{q d s}=\left[\begin{array}{cc}
L_{l s}+L_{m q} & 0 \\
0 & L_{l s}+L_{m d}
\end{array}\right]\left[\begin{array}{c}
i_{q s} \\
i_{d s}
\end{array}\right]+\lambda_{m}\left[\begin{array}{c}
0 \\
1.5
\end{array}\right]
\end{gathered}
$$

The transformations used are:

$$
\begin{aligned}
& v_{q d s}=\left(\begin{array}{ll}
v_{q s} & v_{d s}
\end{array}\right)^{T} \\
& =\left[\begin{array}{cc}
-\sin \left(\theta_{e}\right) & \cos \left(\theta_{e}\right) \\
\cos \left(\theta_{e}\right) & \sin \left(\theta_{e}\right)
\end{array}\right]\left[\begin{array}{ccc}
\frac{3}{2} & 0 & 0 \\
0 & \frac{\sqrt{3}}{2} & -\frac{\sqrt{3}}{2}
\end{array}\right]\left[\begin{array}{c}
v_{a s} \\
v_{b s} \\
v_{c s}
\end{array}\right] \\
& i_{q d s}=\left(\begin{array}{ll}
i_{q s} & i_{d s}
\end{array}\right)^{T} \\
& =\left[\begin{array}{cc}
-\sin \left(\theta_{e}\right) & \cos \left(\theta_{e}\right) \\
\cos \left(\theta_{e}\right) & \sin \left(\theta_{e}\right)
\end{array}\right]\left[\begin{array}{ccc}
\frac{3}{2} & 0 & 0 \\
0 & \frac{\sqrt{3}}{2} & -\frac{\sqrt{3}}{2}
\end{array}\right]\left[\begin{array}{c}
i_{a s} \\
i_{b s} \\
i_{c s}
\end{array}\right]
\end{aligned}
$$

Note: A factor of 1.5 occurs due the transformations used being not quantity equivalent.

$$
T_{e}=\frac{2}{3} \frac{P}{2}\left[1.5 \lambda_{m} i_{q s}+\left(L_{d}-L_{q}\right) i_{q s} i_{d s}\right]
$$

\section{Operation trajectories of IPM motor}

The operating point of IPM motor is decided by the optimization technique used and the operation trajectory is limited by the motor ratings. Therefore, it is necessary to understand the various operation trajectories and limits. The motor expressions are normalized to make them parameters independent.

1. MTPA trajectory of IPM motor is expressed by [1]:

$$
\begin{gathered}
T_{e n}=\frac{i_{q n}+i_{q n} \sqrt{1+4 i_{q n}^{2}}}{2} \\
T_{e n}=\sqrt{i_{d n}\left(i_{d n}-1\right)^{3}} \\
T_{e n}=i_{q n}\left(1-i_{d n}\right)
\end{gathered}
$$

2. MTPV trajectory is expressed as [4]: 


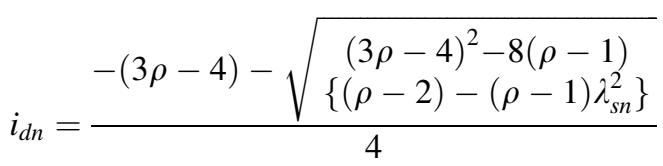

$$
\begin{aligned}
& i_{q n}= \pm\left(\frac{\rho-1}{\rho}\right) \sqrt{\lambda_{s n}^{2}-\left(1+\frac{i_{d n}}{\rho-1}\right)^{2}}
\end{aligned}
$$

3. The current limit locus is defined as:

$$
i_{d n}^{2}+i_{q n}^{2} \leq i_{s n r}^{2}
$$

$i_{\mathrm{snr}}$ is the rated normalized current of the motor.

4. The voltage limit locus is defined as:

$$
\sqrt{\left(1+\frac{i_{d n}}{\rho-1}\right)^{2}+\left(\frac{\rho i_{q n}}{\rho-1}\right)^{2}} \leq \lambda_{s n}
$$

where the parameters are normalized as:

$$
\begin{aligned}
& T_{e b}=\frac{2}{3} \frac{P}{2} 1.5 \lambda_{m}^{r} i_{b}, T_{e n}=\frac{T_{e}}{T_{e b}}, i_{b}=\frac{1.5 \lambda_{m}^{r}}{L_{q}-L_{d}}, i_{s n}=\frac{i_{s}}{i_{b}}, \\
& i_{q n}=\frac{i_{q s}}{i_{b}}, i_{d n}=\frac{i_{d s}}{i_{b}}, \lambda_{b}=1.5 \lambda_{m}^{r}, \lambda_{s n}=\frac{\lambda_{s}}{\lambda_{b}}, \text { and } \rho=\frac{L_{q}}{L_{d}}
\end{aligned}
$$

Also,

$$
\begin{gathered}
\lambda_{s n}=\sqrt{\left(1+\frac{i_{d n}}{\rho-1}\right)^{2}+\left(\frac{\rho i_{q n}}{\rho-1}\right)^{2}} \\
\lambda_{s}=\frac{V_{d q}}{\omega_{e}}=\frac{\sqrt{\left(v_{q s}\right)^{2}+\left(v_{d s}\right)^{2}}}{\omega_{e}} \\
i_{s}^{2}=i_{d s}^{2}+i_{q s}^{2}
\end{gathered}
$$

The operation trajectories expressed in (7)-(13) are shown figure 1 . The MTPV trajectory lies either inside of current limit locus or out of current limit locus depending on the motor parameters and rating. For the chosen IPM motor ("Appendix"), the MTPV trajectory as shown in figure 1, lies outside of current limit locus and thus outside the range of operation.

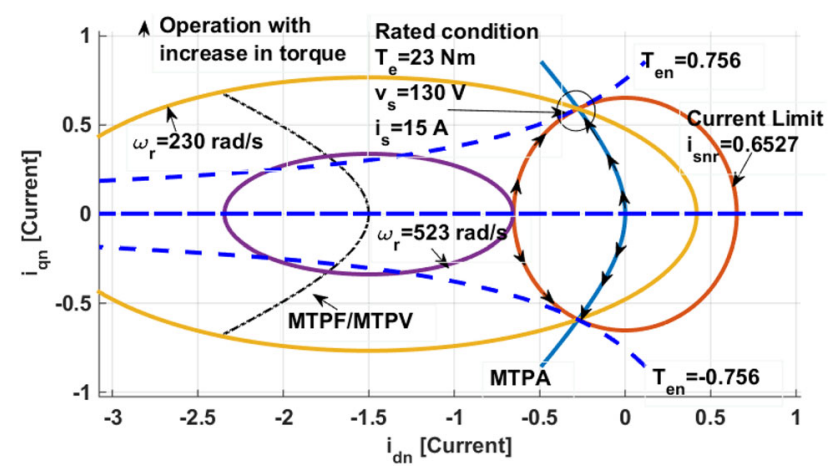

Figure 1. Operation trajectories of IPM motor.

\section{Voltage minimization control of IPM motor}

The voltage minimization trajectory defined as the maximum torque per voltage i.e., MTPV lies outside of current limit locus and therefore the voltage minimization technique operation lies along the current limit locus which is the closest operating point to MTPV trajectory. Two cases are shown in figures 2 and 3, for current minimization and voltage minimization, respectively. One with rated DC-link voltage and rated operating speed of $\omega_{\mathrm{r}}=230 \mathrm{rad} / \mathrm{s}$ and a second case with rated DC-link voltage and operating speed of $\omega_{\mathrm{r}}=314 \mathrm{rad} / \mathrm{s}$, where the operation is under fieldweakening due to saturation of voltage limit. The trajectories are shown for operation at constant speed, with an increase in load. The current minimization technique operates along MTPA trajectory [shown in blue colour, figure 2(a)] as long as the motor operates under rated load i.e., operating speed $\omega_{\mathrm{r}} \leq 230 \mathrm{rad} / \mathrm{s}$. The operation at higher speeds would trace either MTPA or the voltage limit ellipse, depending on the operating speed and load. As shown in figure 2(b) [yellow colour], for the IPM motor operating at a speed $\omega_{\mathrm{r}}=314 \mathrm{rad} / \mathrm{s}$, the trajectory traced with an increase in load is along voltage limit ellipse corresponding to the speed of $314 \mathrm{rad} / \mathrm{s}$ [2]. The voltage minimization control traces the current limit locus. The operation is always along the current limit locus irrespective of operation in field-weakening [shown in orange

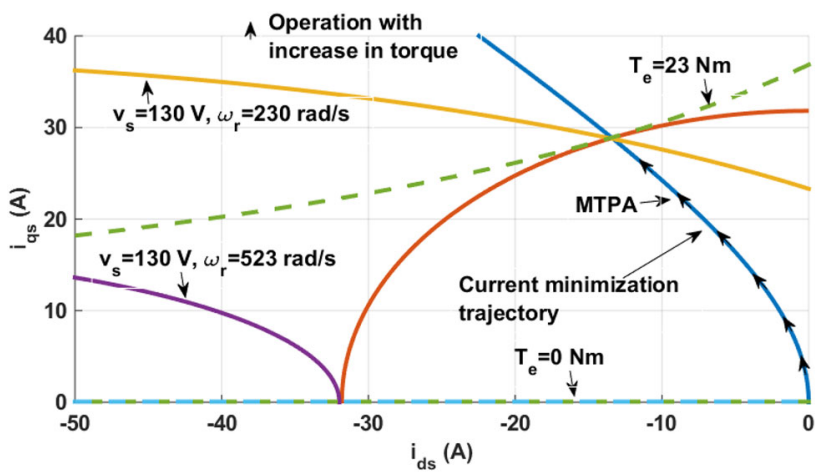

(a)

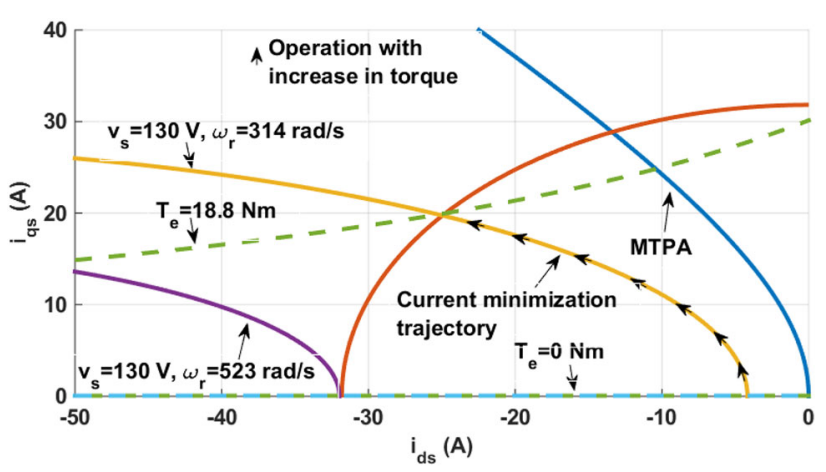

(b)

Figure 2. Current minimization control trajectory with increase in load at constant speed. (a) $\omega_{\mathrm{r}}=230 \mathrm{rad} / \mathrm{s}, \mathrm{v}_{\mathrm{s}}=130 \mathrm{~V}$, and (b) $\omega_{\mathrm{r}}=314 \mathrm{rad} / \mathrm{s}, \mathrm{v}_{\mathrm{s}}=130 \mathrm{~V}$. 


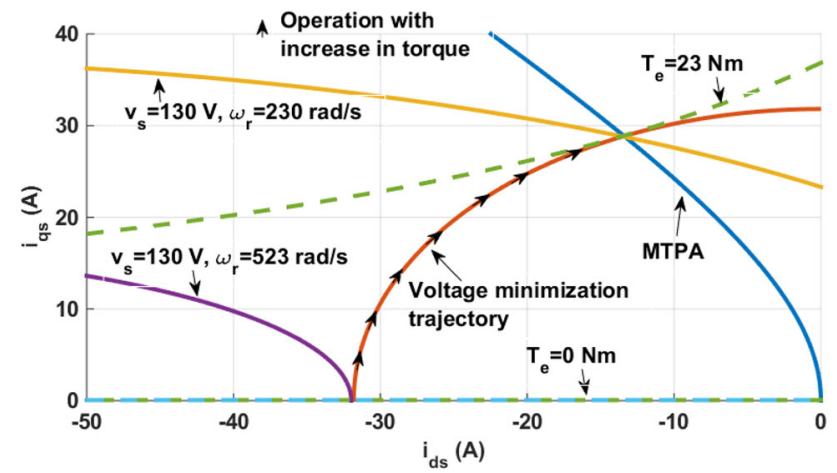

(a)

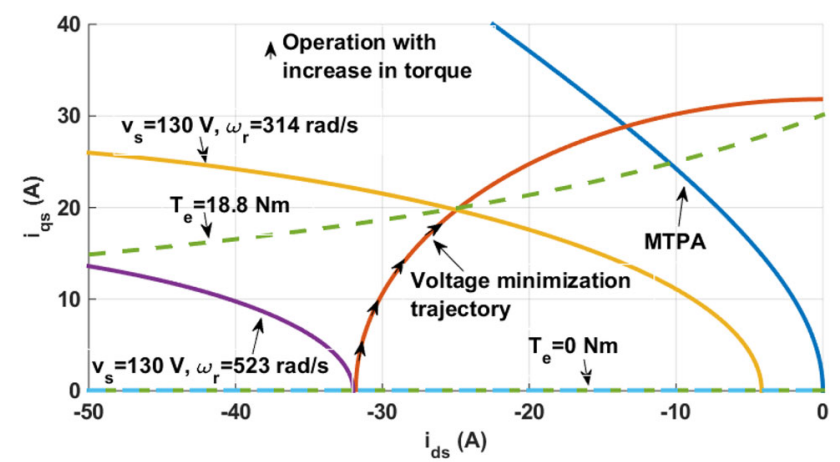

(b)

Figure 3. Voltage minimization control trajectory with increase in load at constant speed. (a) $\omega_{\mathrm{r}}=230 \mathrm{rad} / \mathrm{s}, \mathrm{v}_{\mathrm{s}}=130 \mathrm{~V}$ and (b) $\omega_{\mathrm{r}}=314 \mathrm{rad} / \mathrm{s}, \mathrm{v}_{\mathrm{s}}=130 \mathrm{~V}$.

colour, figure 3]. Though, the onset of field-weakening i.e., either due to increase in operating speed beyond rated or reduction in DC-link voltage, causes a reduction in maximum developed torque as the voltage-limit locus shrinks [figure 3(b)]. Theoretically, the maximum operating speed of the IPM motor is $\omega_{\mathrm{r}}=525 \mathrm{rad} / \mathrm{s}$.

The voltage minimization trajectory is defined by the intersection of current limit locus and the constant torque locus, decided by the load. Using (9) and (12), the quartic defining the voltage minimization locus is given by:

$$
i_{d n}^{4}-2 i_{d n}^{3}+i_{d n}^{2}\left(1-i_{s n r}^{2}\right)+2 i_{s n r}^{2} i_{d n}+\left(T_{e n}^{2}-i_{s n r}^{2}\right)=0
$$

Expression (17) is solved using Ferrari's method of quartic [6]. Using $i_{\text {snr }}=0.6526$, the determinant of (17) is given as

$$
\begin{aligned}
D= & 15.7802 T_{e n}^{2}+183\left(T_{e n}^{2}-0.4259\right)^{2} \\
& +256\left(T_{e n}^{2}-0.4259\right)^{3}-13.5236
\end{aligned}
$$

It is seen that the determinant given by (18) is negative for $\mathrm{T}_{\mathrm{en}}=\{-23 \mathrm{Nm}, 23 \mathrm{Nm}\} \quad$ (Matlab/Simulink is used to study the nature of determinant ' $\mathrm{D}$ ' for different $\mathrm{T}_{\mathrm{en}}$ ). Negative determinant indicates two real and two complex conjugate roots for the quartic (17). This is expected, as the current locus intersects $T_{e n}$ at two real points [figure 2(b)]. Of the two real roots, the one lying in the 2nd quadrant is the required solution. Thus, $i_{d n}$ and $i_{\text {qn }}$ for a given required torque $T_{e n}$ are given by:

$$
\left(i_{d n}, i_{q n}\right)=\left(-\frac{\mathrm{A}}{4}-\frac{\eta}{2}-\frac{\mu}{2}, \frac{T_{e n}}{\left(1-i_{d n}\right)}\right)
$$

where,

$$
\begin{aligned}
\mathrm{A} & =-2, \mathrm{~B}=0.5741, \mathrm{C}=0.85177, \text { and } \mathrm{D}=T_{e n}^{2} \\
& -0.4259[\text { Expression }(17)]
\end{aligned}
$$

Also

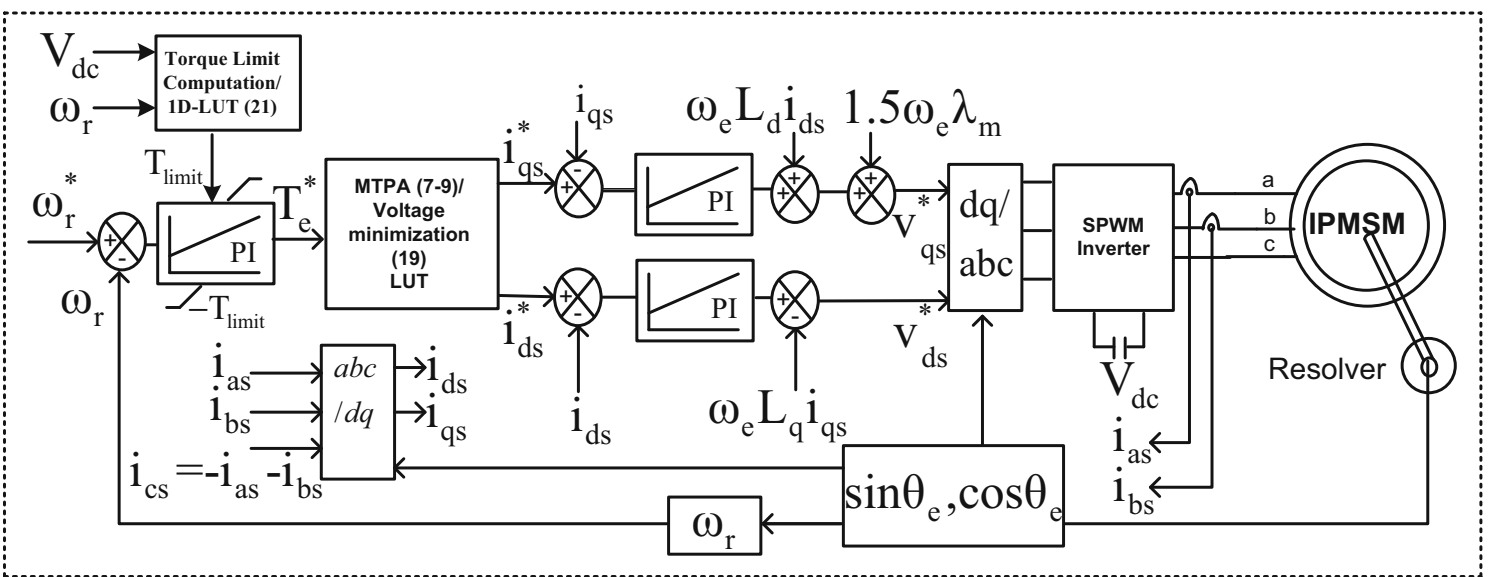

Figure 4. Basic control block diagram for vector control of IPM motor. 


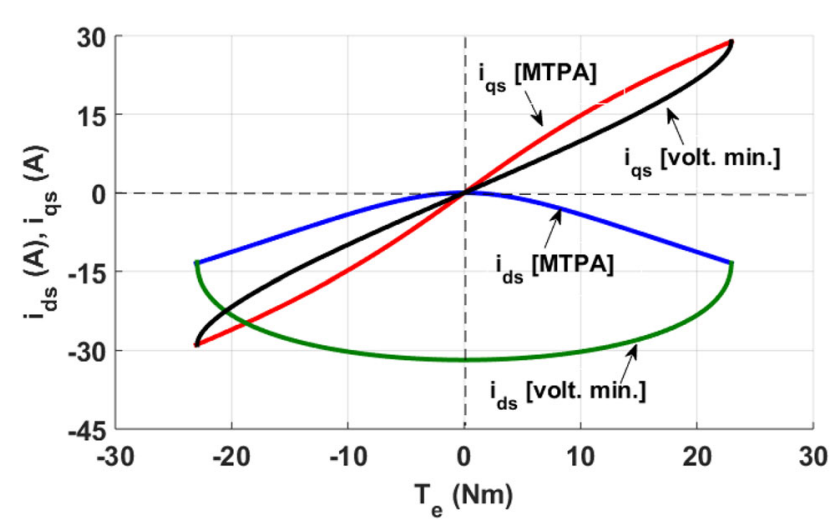

Figure 5. MTPA and voltage minimization relation of $\mathrm{T}_{\mathrm{e}}, \mathrm{i}_{\mathrm{ds}}$ and $\mathrm{i}_{\mathrm{qs}}$.

$$
\begin{aligned}
& \alpha=\mathrm{AC}-4 \mathrm{D}-\frac{\mathrm{B}^{2}}{3}, \\
& \beta=\frac{1}{27}\left(-2 B^{3}+9 A B C+72 B D-27 C^{2}-27 A^{2} D\right) \\
& \gamma=\frac{B}{3}+\sqrt[3]{-\frac{\beta}{2}+\sqrt{\frac{\beta^{2}}{4}+\frac{\alpha^{3}}{27}}}+\sqrt[3]{-\frac{\beta}{2}-\sqrt{\frac{\beta^{2}}{4}+\frac{\alpha^{3}}{27}}}, \\
& \eta=\sqrt{\frac{\mathrm{A}}{4}-\mathrm{B}+\gamma}, \text { and } \\
& \mu=\sqrt{\frac{3}{4} A^{2}-\eta^{2}-2 B-\frac{1}{4 \eta}\left(4 A B-8 C-A^{3}\right)}
\end{aligned}
$$

\section{Control algorithm}

The control block diagram for implementation of vector controlled IPM Motor is shown in figure 4. The inner loop comprises of $i_{\text {ds }}$ and $i_{\text {qs }}$ i.e., the direct axis current control and the quadrature axis current control. The speed control forms the outer loop. The three Proportional Integral (PI) are designed utilizing the mathematical model of IPM motor, to provide stable closed-loop control with a negligible steady-state error. The torque command $T_{e}$ decides the current command $\mathrm{i}_{\mathrm{ds}}$ and $\mathrm{i}_{\mathrm{qs}}$ based on the optimization technique used. This is done using a LUT (figure 5) developed utilizing expression (7)-(9) for MTPA and expression (19) for voltage minimization control. A twolevel inverter is used, which is operated using Sine Pulse Width Modulation (SPWM) with maximum modulation index $\mathrm{m}_{\mathrm{a}}=0.9$ and switching frequency $\mathrm{f}_{\mathrm{s}}=10 \mathrm{KHz}$.

The maximum torque developed depends on the DC-link voltage and the operating speed. As the operation enters field weakening, either due to a reduction in DC-link voltage, or due to increase in operation speed, the maximum torque capability is reduced. The torque limit expression is derived using current limit locus (15) and voltage limit locus (16) as:

$$
\left(L_{d}^{2}-L_{q}^{2}\right) i_{d s}^{2}+\left(3 \lambda_{m} L_{d}\right) i_{d s}+L_{q}^{2} i_{s r}^{2}-\lambda_{s \_ \text {limit }}^{2}+\left(1.5 \lambda_{m}\right)^{2}=0
$$

Solving equation (20) gives

$$
i_{d s \lim }=\frac{-b+\sqrt{b^{2}-4 a c}}{2 a}
$$

where

$$
\begin{aligned}
& a=L_{d}^{2}-L_{q}^{2}, b=3 \lambda_{m} L_{d}, \text { and } c=L_{q}^{2} i_{s r}^{2}-\lambda_{s \_ \text {limit }}^{2}+\left(1.5 \lambda_{m}\right)^{2} \\
& i_{q s \lim }= \pm \sqrt{i_{s r}^{2}-i_{d s \lim }^{2}}
\end{aligned}
$$

$\mathrm{i}_{\mathrm{sr}}$ is the rated peak current in dq reference frame.

$$
T_{\text {limit }}=\frac{2 P}{3} \frac{P}{2}\left[1.5 \lambda_{m} i_{q s \lim }+\left(L_{d}-L_{q}\right) i_{q s \lim } i_{d s \lim }\right]
$$

Here, $\lambda_{\mathrm{s}_{\_} \text {limit }}=\mathrm{V}_{\mathrm{dq} \_\mathrm{r}} \mathrm{r} / \omega_{\mathrm{e}}$ is the limiting / maximum flux decided by the DC-link voltage or maximum phase voltage. $\mathrm{V}_{\mathrm{dq} \_\mathrm{r}}=\mathrm{KV}_{\mathrm{dc}}, \mathrm{K}$ depends on PWM technique used i.e., SPWM or SVPWM. The torque limit for given operating speed and DC-link voltage is given by (21).

\section{Simulation results}

Simulation studies are performed for the proposed voltage minimization control in comparison to the MTPA control using MATLAB/Simulink. The simulation results are provided in figures 6 and 8 . The speed response, variation of direct axis current $i_{d s}$ and quadrature axis current $i_{q s}$ with the application of load, the torque-speed characteristics and the $\mathrm{i}_{\mathrm{ds}}-\mathrm{i}_{\mathrm{qs}}$ trajectory traced with load, are shown in figure 6 and figure 7 for voltage minimization control and MTPA control, respectively. As explained in section 4 , the voltage minimization control trajectory is traced along the current limit locus even under no-load. Thus, irrespective of the loading condition, the IPM motor under voltage-minimization draws rated current. This is indicated in figures 6 and 7 , time $\mathrm{t}=1.5-2 \mathrm{~s}$ which shows the no-load operating condition at $\omega_{\mathrm{r}}=230 \mathrm{rad} / \mathrm{s}$. The currents drawn $\mathrm{i}_{\mathrm{ds}}=-31.76 \mathrm{~A}$ and $\mathrm{i}_{\mathrm{qs}}=1.78 \mathrm{~A}$, along voltage minimization control indicate higher magnitude of currents drawn as compared to control along MTPA ( $i_{\text {ds- }}$ $=-0.17 \mathrm{~A}$ and $\mathrm{i}_{\mathrm{qs}}=2.94 \mathrm{~A}$ ). The variation of $\mathrm{i}_{\mathrm{ds}}$ and $\mathrm{i}_{\mathrm{qs}}$ with a gradual increase in load $[\mathrm{t}=2-4 \mathrm{~s}]$ is shown in figures 6(c) and (d) for control following voltage minimization, and in figures 7(c) and (d) for control following MTPA. The trajectories traced by $i_{d s}-i_{q s}$ are shown in figure 6(f) and figure 7(f) for voltage minimization and MTPA, respectively. The trajectory traced along voltage minimization [figure 6(f)] is the current limit locus. The torque-speed characteristics of the drive are shown in figure 6(e) and figure 7(e) for the two control techniques. MTPA optimizes the current drawn. The dq-axes voltages 


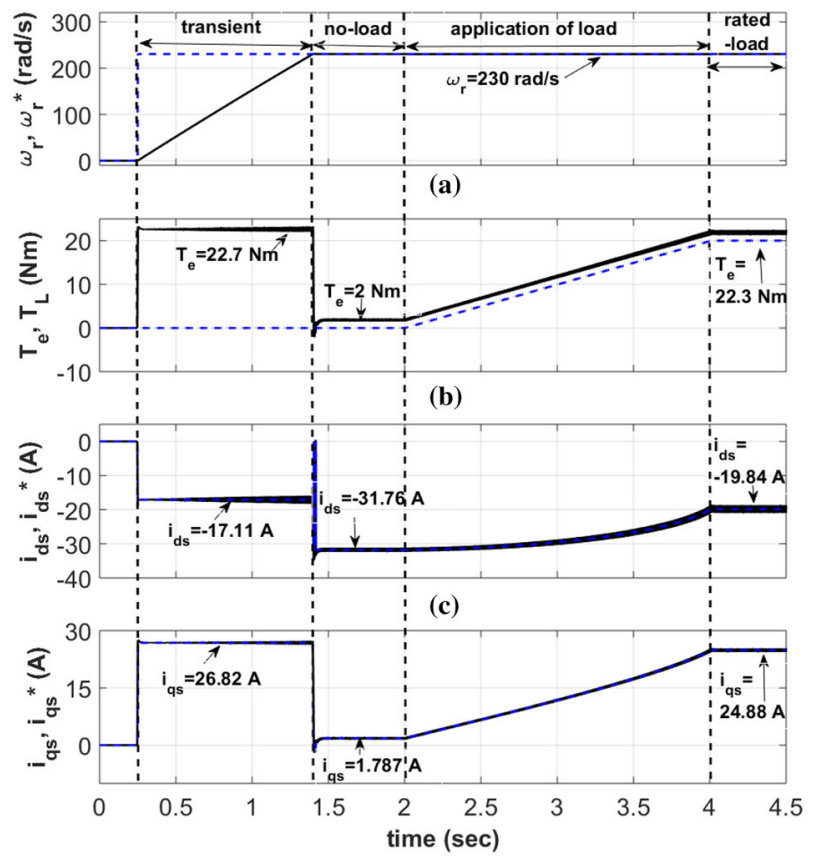

(d)

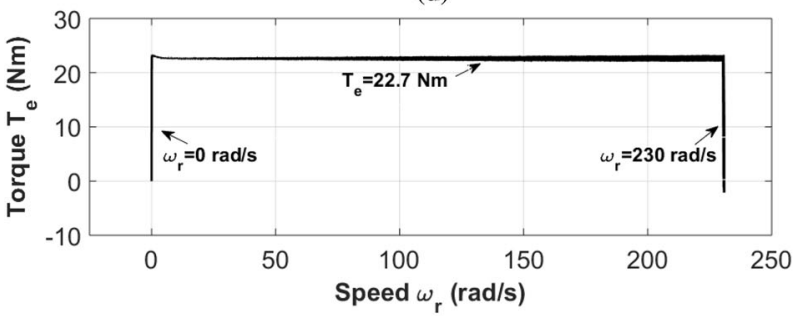

(e)

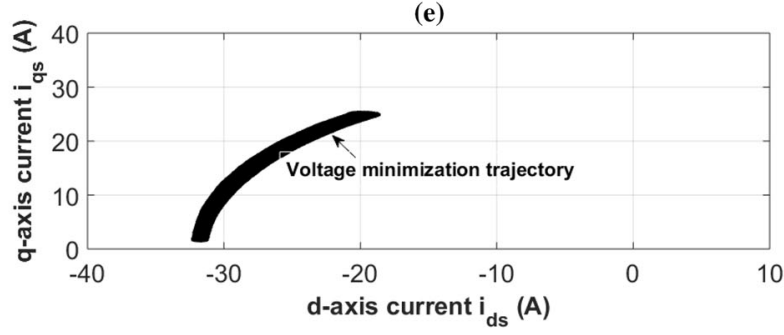

(f)

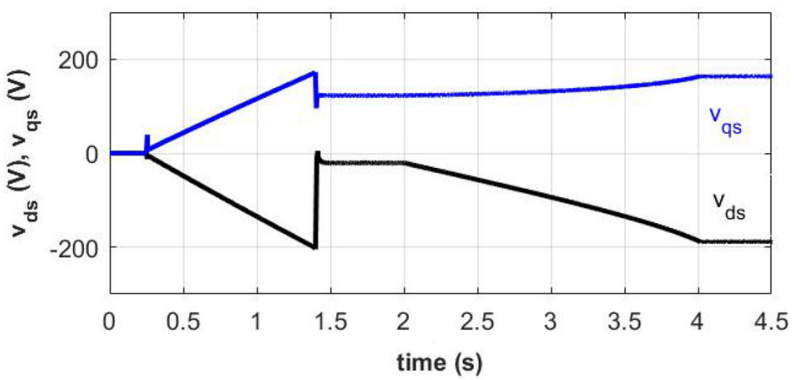

(g)

Figure 6. Simulation results following voltage minimization control technique. (a) Speed $\omega_{\mathrm{r}}$ and speed reference $\omega_{\mathrm{r}}{ }^{*}$, (b) developed torque $T_{e}$ and load torque $T_{L},\left(\right.$ c) d-axis current $i_{d s}$ and reference $\mathrm{i}_{\mathrm{ds}} *$, (d) $\mathrm{q}$-axis current $\mathrm{i}_{\mathrm{qs}}$ and reference $\mathrm{i}_{\mathrm{qs}} *$, (e) torquespeed characteristics, and (f) $\mathrm{i}_{\mathrm{ds}}-\mathrm{i}_{\mathrm{qs}}$ trajectory followed and (g) filtered dq-axes voltage $v_{\mathrm{ds}}$ and $\mathrm{v}_{\mathrm{qs}}$.

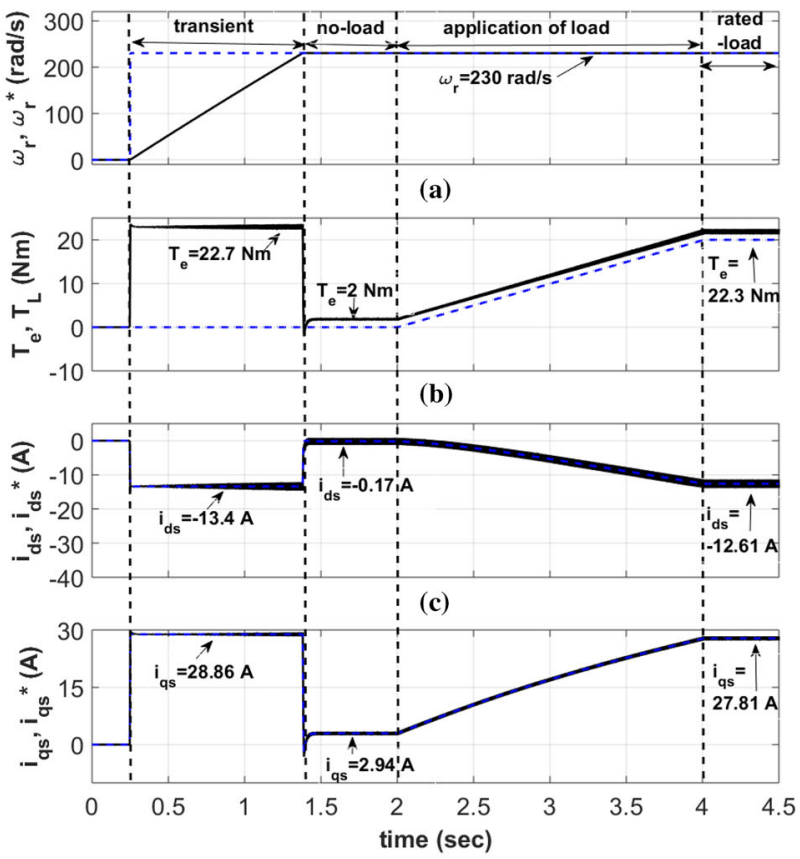

(d)

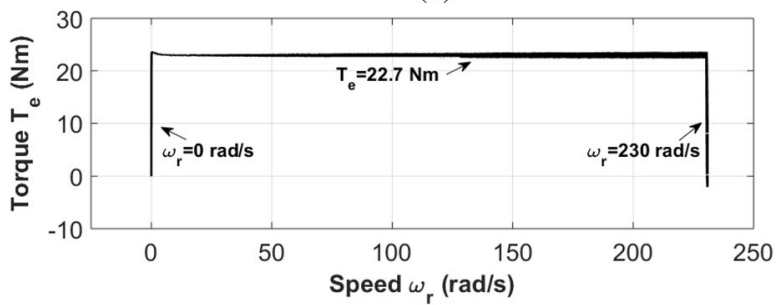

(e)

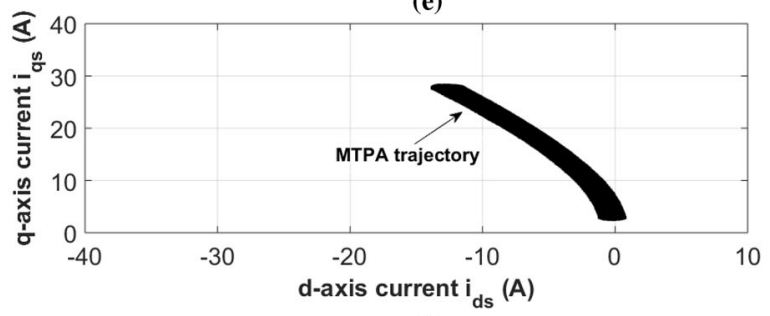

(f)

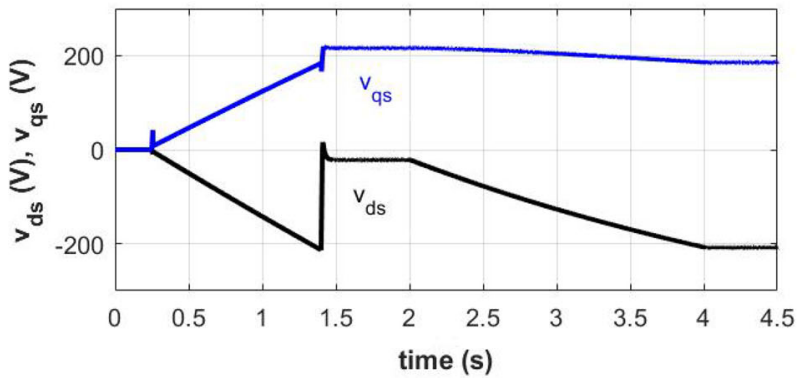

(g)

Figure 7. Simulation results following MTPA control technique. (a) Speed $\omega_{\mathrm{r}}$ and speed reference $\omega_{\mathrm{r}}{ }^{*}$, (b) developed torque $\mathrm{T}_{\mathrm{e}}$ and load torque $\mathrm{T}_{\mathrm{L}}$, (c) d-axis current $\mathrm{i}_{\mathrm{ds}}$ and reference $\mathrm{i}_{\mathrm{ds}}{ }^{*}$, (d) q-axis current $\mathrm{i}_{\mathrm{qs}}$ and reference $\mathrm{i}_{\mathrm{qs}} *$, (e) torque-speed characteristics, and (f) $\mathrm{i}_{\mathrm{ds}}-\mathrm{i}_{\mathrm{qs}}$ trajectory followed and (g) filtered dq-axes voltage $\mathrm{v}_{\mathrm{ds}}$ and $\mathrm{v}_{\mathrm{qs}}$. 


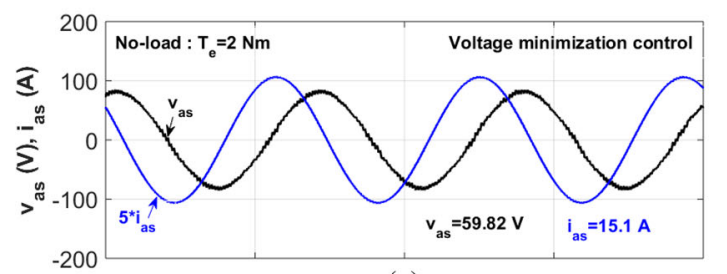

(a)

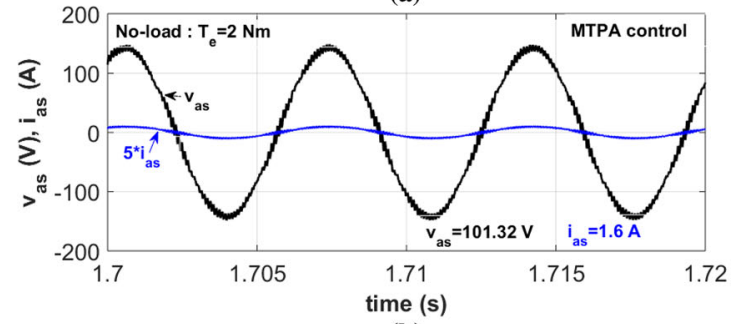

(b)
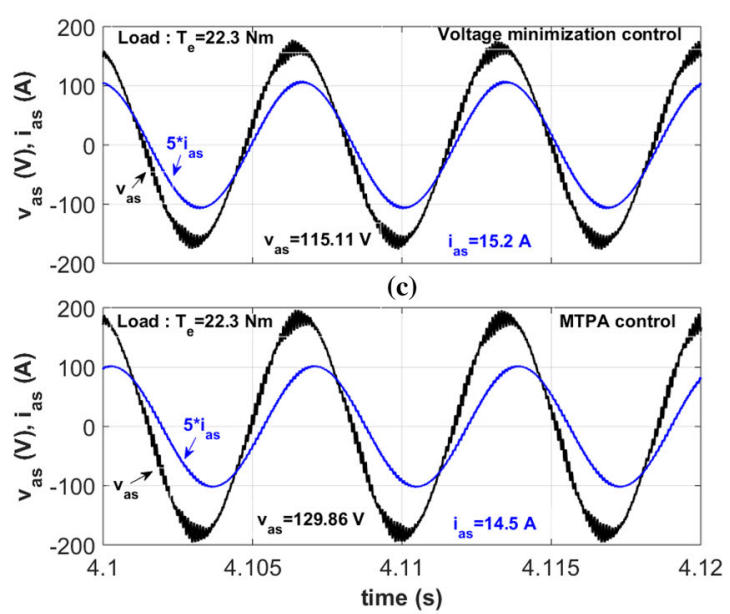

(d)

Figure 8. Simulation results showing phase voltage and phase current. (a) $v_{a s}$ and $i_{a s}$ following voltage minimization control $\left(\mathrm{T}_{\mathrm{e}}=2 \mathrm{Nm}, \omega_{\mathrm{r}}=230 \mathrm{rad} / \mathrm{s}\right),(\mathbf{b}) \mathrm{v}_{\mathrm{as}}$ and $\mathrm{i}_{\mathrm{as}}$ following MTPA control $\left(\mathrm{T}_{\mathrm{e}}=2 \mathrm{Nm}, \omega_{\mathrm{r}}=230 \mathrm{rad} / \mathrm{s}\right),(\mathbf{c}) \mathrm{v}_{\mathrm{as}}$ and $\mathrm{i}_{\mathrm{as}}$ following voltage minimization control $\left(\mathrm{T}_{\mathrm{e}}=22.3 \mathrm{Nm}, \omega_{\mathrm{r}}=230 \mathrm{rad} / \mathrm{s}\right)$, and $(\mathbf{d}) \mathrm{v}_{\mathrm{as}}$ and $\mathrm{i}_{\mathrm{as}}$ following MTPA control $\left(\mathrm{T}_{\mathrm{e}}=22.3 \mathrm{Nm}, \omega_{\mathrm{r}}=230 \mathrm{rad} / \mathrm{s}\right)$.
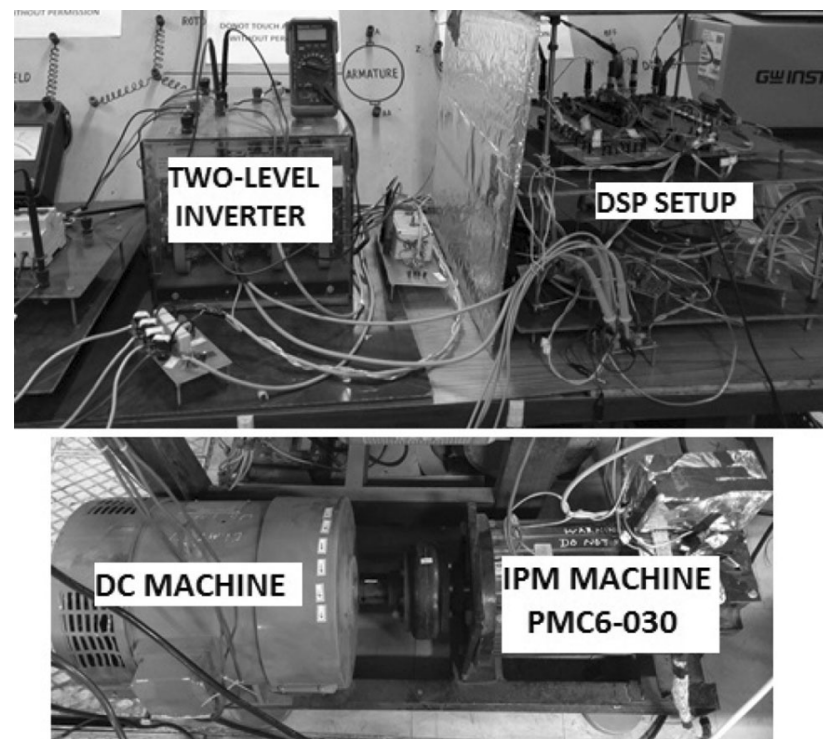

Figure 9. Experimental set-up - IPM motor coupled to DC machine, two-level inverter and DSP set-up.

are also shown in figure $6(\mathrm{~g})$ and figure $7(\mathrm{~g})$ for the two control strategies.

To understand the voltage minimization operation, it is necessary to compare the voltage and current magnitudes. The phase voltage and phase current for operation along voltage minimization and MTPA are shown in figure 8 . The phase voltage $v_{a s}$ is derived using the reference wave of SPWM corresponding to phase A as: $\mathrm{v}_{\mathrm{as}}=0.5 \mathrm{v}_{\mathrm{asc}} \mathrm{V}_{\mathrm{dc}} \cdot \mathrm{V}_{\mathrm{dc}}$ is the DC-link voltage and $v_{\text {asc }}$ is the per unit reference wave. The phase voltage and phase current under no-load and $\omega_{\mathrm{r}}=230 \mathrm{rad} / \mathrm{s}$ are shown in figures $8(\mathrm{a})$ and (b), for operation along voltage minimization and MTPA, respectively. Also, the phase voltage and phase current under load $\mathrm{T}_{\mathrm{e}}=22.3 \mathrm{Nm}$ and $\omega_{\mathrm{r}}=230 \mathrm{rad} / \mathrm{s}$ are shown in figures $8(\mathrm{c})$ and (d), for operation along voltage minimization and MTPA, respectively. As seen in figure 8(a) and (c), the current drawn is rated $\left(\left|i_{\text {as }}\right|=15 \mathrm{~A}\right)$ irrespective of the load when the control is along voltage minimization. On the other hand, the voltage drawn is less compared to operation along MTPA control. The voltage drawn at no-load is $\mathrm{v}_{\text {as- }}$ $=59.8 \mathrm{~V}$ along voltage minimization and $\mathrm{v}_{\mathrm{as}}=101.3 \mathrm{~V}$ along MTPA control. The voltage drawn at load $\mathrm{T}_{\mathrm{e}}=22.3$ is $\mathrm{v}_{\mathrm{as}}=115.1 \mathrm{~V}$ along voltage minimization and $\mathrm{v}_{\text {as- }}$ $=129.8 \mathrm{~V}$ along MTPA control.

Design of PI controllers: The control algorithm shown in figure 4 contains three PI controllers, one for outerloop speed control and two inner current control loops for direct and quadrature axis, respectively. The controller gains are given in the appendix. The inner current PI controller is designed such that the PI time-constant cancels the largest time constant in the current loop i.e., $\mathrm{T}_{\mathrm{c}}=\mathrm{L}_{\mathrm{d}} / \mathrm{r}_{\mathrm{s}}$ and $\mathrm{L}_{\mathrm{q}} / \mathrm{r}_{\mathrm{s}}$ for $\mathrm{d}$-axis and $\mathrm{q}$-axis, respectively. The proportional gains of current controller are designed as to have a damping factor of 0.707 for the inner current loops. The outer speed controller PI is designed keeping a phase margin of 56degrees. The PI controllers have limited integration to avoid over-flow of integral components. The outputs of the current PI controllers are limited to avoid over-modulation. Also, the output of outer speed PI controller is limited as per the torque-limit defined by (21). A different set of PI control gains are designed for experimental implementation based on prior design values from simulation and manual tuning in a step-wise manner. 


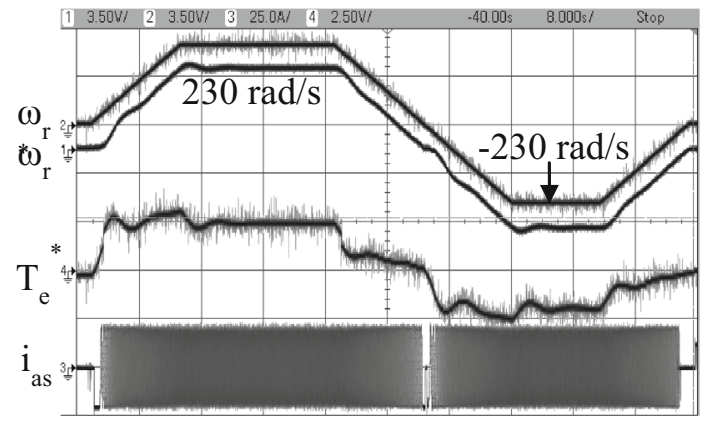

(a)

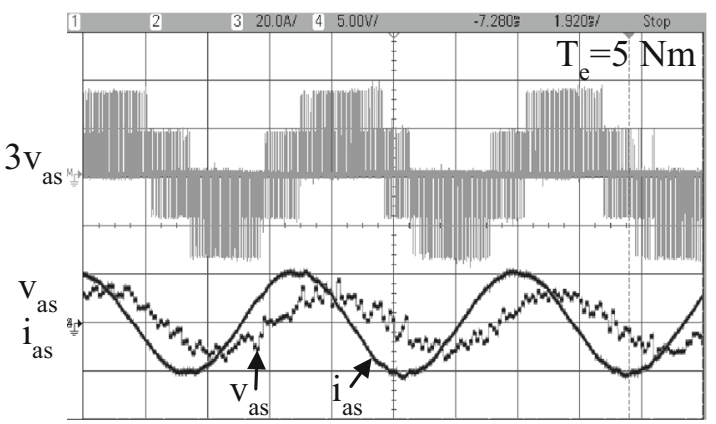

(c)

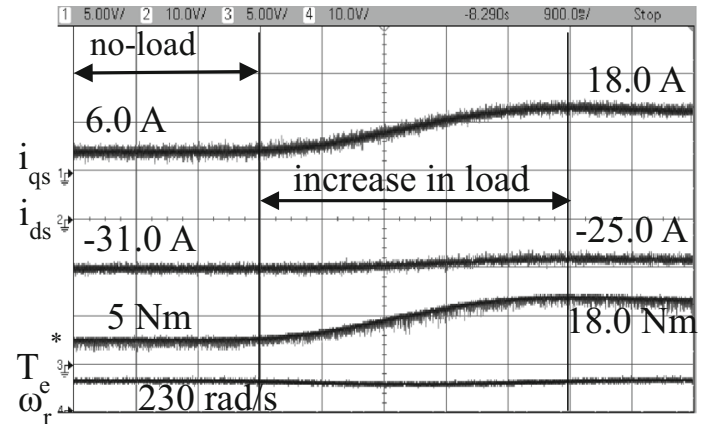

(b)

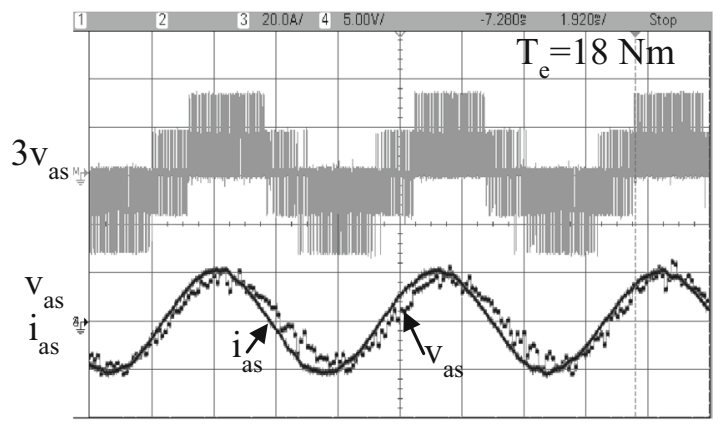

(d)

Figure 10. Experimental results of IPM motor following voltage minimization control technique. (a) The speed response $\omega_{\mathrm{r}}$ and $\omega_{\mathrm{r}} *$ $\left[\omega_{\mathrm{r}}-140 \mathrm{rad} / \mathrm{s} / \mathrm{div}, \mathrm{T}_{\mathrm{e}}-6.8 \mathrm{Nm} / \mathrm{div}, \mathrm{i}_{\mathrm{as}}-25 \mathrm{~A} / \mathrm{div}\right.$, and $\left.\mathrm{t}-8 \mathrm{~s} / \mathrm{div}\right]$, (b) the variation of $\mathrm{i}_{\mathrm{ds}}$ and $\mathrm{i}_{\mathrm{qs}}$ with application of load [ $\omega_{\mathrm{r}}-400 \mathrm{rad} / \mathrm{s} / \mathrm{div}$, $\mathrm{T}_{\mathrm{e}}-13.6 \mathrm{Nm} / \mathrm{div}, \mathrm{i}_{\mathrm{qs}}-15 \mathrm{~A} / \mathrm{div}, \mathrm{i}_{\mathrm{ds}}-30 \mathrm{~A} / \mathrm{div}$ and $\left.\mathrm{t}-0.9 \mathrm{~s} / \mathrm{div}\right]$, (c) the phase voltage $\mathrm{v}_{\mathrm{as}}$ and phase current $\mathrm{i}_{\mathrm{as}}$ under no-load $\left(\omega_{\mathrm{r}}=230 \mathrm{rad} / \mathrm{s}\right.$, $\left.\mathrm{T}_{\mathrm{e}}=5 \mathrm{Nm}\right)$, and $(\mathbf{d})$ the phase voltage $\mathrm{v}_{\mathrm{as}}$ and phase current $\mathrm{i}_{\mathrm{as}}$ under load $\left(\omega_{\mathrm{r}}=230 \mathrm{rad} / \mathrm{s}, \mathrm{T}_{\mathrm{e}}=18 \mathrm{Nm}\right)\left[\mathrm{i}_{\mathrm{as}}-20 \mathrm{~A} / \mathrm{div}, \mathrm{v}_{\mathrm{as}}-150 / \mathrm{div}\right.$, $\mathrm{V}_{\text {as }}=500 \mathrm{~V} / \mathrm{div}$ and $\left.\mathrm{t}-1.92 \mathrm{~ms} / \mathrm{div}\right]$.

\section{Experimental results}

The voltage minimization control is demonstrated using a 5.5 KW IPM motor (PMC6-030) manufactured by Moog. The IPM motor parameters are given in the appendix. The IPM machine is coupled to a dc-machine which is operated as a generator to electrically load the IPM motor. The drive is controlled using Texas Instruments TMS320F28335 digital signal processor. SPWM is used with a maximum modulation index of 0.9 and switching at $10 \mathrm{KHz}$. The experimental set-up is shown in figure 9. Current minimization is discussed with operation along MTPA. Also, the developed torque may vary slightly under the same operating condition, when the control is changed between voltage minimization and MTPA. This is due to parameter uncertainties.

The experimental results are shown in figures $10-12$. Figure 10 shows the experimental results of vector controlled IPM motor following voltage minimization control technique and figure 11 shows the experimental results following MTPA control technique. The speed response of the motor is shown in figure 10(a). As expected [figure 3], the operation along voltage minimization is always along the current limit locus, irrespective of the operating speed and load. The current magnitude as seen in figure 10(a) indicates the operation at constant current i.e., rated current, irrespective of the operating speed and load torque. The operation along MTPA control [figure 11(a)] is at a reduced current, decided by the developed torque.

The variation of direct axis current $i_{\mathrm{ds}}$ and quadrature axis current $\mathrm{i}_{\mathrm{qs}}$ with an increase in load is shown in figures 10 (b) and figure 11(b), for operation along voltage minimization and MTPA, respectively. The IPM motor is operating at speed $\omega_{\mathrm{r}}=230 \mathrm{rad} / \mathrm{s}$. The direct axis current $\mathrm{i}_{\mathrm{ds}}=-31 \mathrm{~A}$ and quadrature axis current $\mathrm{i}_{\mathrm{qs}}=6 \mathrm{~A}$, drawn under no-load when the operation is along voltage minimization control, indicates rated current magnitude drawn. The no-load currents drawn along MTPA are $i_{\mathrm{ds}}=-0.68$ $\mathrm{A}$ and $\mathrm{i}_{\mathrm{qs}}=5 \mathrm{~A}$. Along, both voltage minimization and current minimization, increase in load causes increase in the quadrature axis current drawn. On the other hand, the direct axis current reduces with increase in load for voltage minimization and increases with increase in load for current minimization. These results can be correlated to simulation results given in figures 6(c), (d), figures $7(\mathrm{c})$ and $7(\mathrm{~d})$.

Phase voltage $v_{\text {as }}$ and phase current $i_{\text {as }}$ at no-load and at loaded conditions are shown in figures $10(\mathrm{c})$ and 10(d) for operation along voltage minimization control, and in 


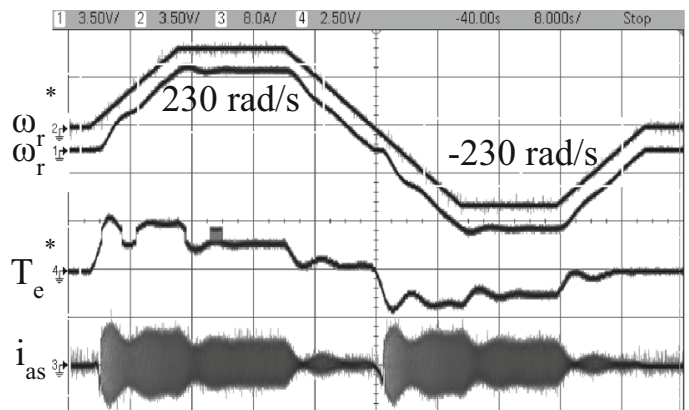

(a)

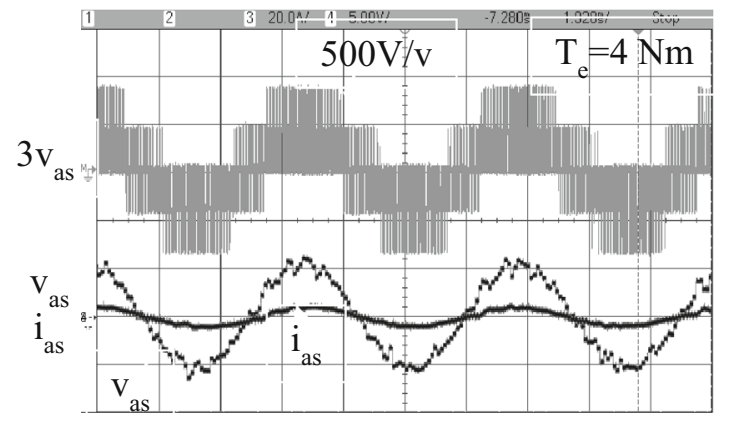

(c)

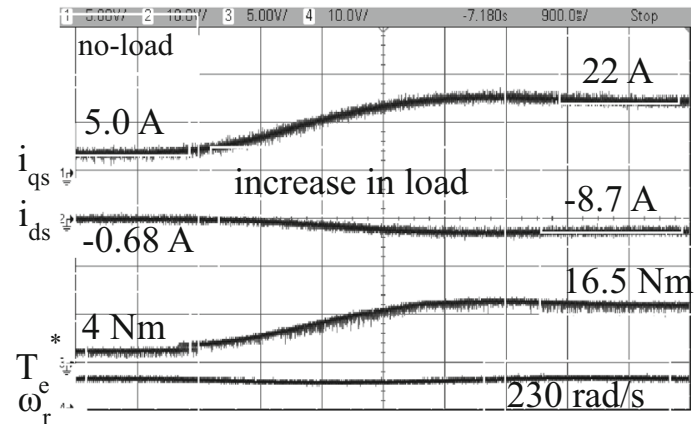

(b)

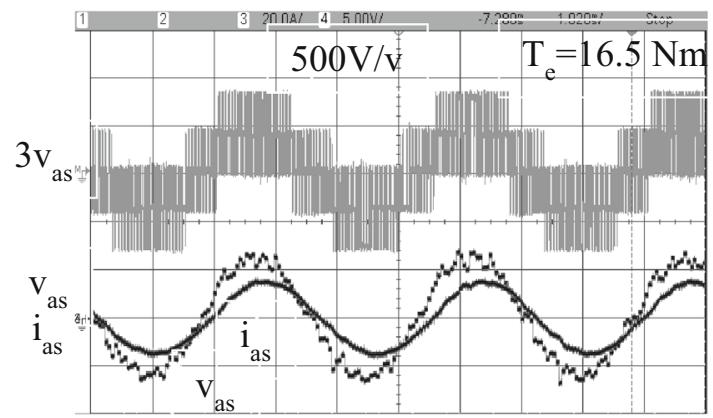

(d)

Figure 11. Experimental results of IPM motor following voltage minimization control technique. (a) The speed response $\omega_{\mathrm{r}}$ and $\omega_{\mathrm{r}}{ }^{*}$ [ $\omega_{\mathrm{r}}-140 \mathrm{rad} / \mathrm{s} / \mathrm{div}, \mathrm{T}_{\mathrm{e}}-6.8 \mathrm{Nm} / \mathrm{div}, \mathrm{i}_{\mathrm{as}}-8 \mathrm{~A} / \mathrm{div}$, and $\left.\mathrm{t}-8 \mathrm{~s} / \mathrm{div}\right],(\mathbf{b})$ the variation of $\mathrm{i}_{\mathrm{ds}}$ and $\mathrm{i}_{\mathrm{qs}}$ with application of load [ $\omega_{\mathrm{r}}-400 \mathrm{rad} / \mathrm{s} / \mathrm{div}, \mathrm{T}_{\mathrm{e}}{ }^{-}$ $13.6 \mathrm{Nm} / \mathrm{div}, \mathrm{i}_{\mathrm{qs}}-15 \mathrm{~A} / \mathrm{div}, \mathrm{i}_{\mathrm{ds}}-30 \mathrm{~A} / \mathrm{div}$ and $\left.\mathrm{t}-0.9 \mathrm{~s} / \mathrm{div}\right]$, (c) the phase voltage $\mathrm{v}_{\mathrm{as}}$ and phase current $\mathrm{i}_{\mathrm{as}}$ under no-load $\left(\omega_{\mathrm{r}}=230 \mathrm{rad} / \mathrm{s}\right.$, $\left.\mathrm{T}_{\mathrm{e}}=4 \mathrm{Nm}\right)$, and $(\mathbf{d})$ the phase voltage $\mathrm{v}_{\mathrm{as}}$ and phase current $\mathrm{i}_{\mathrm{as}}$ under load $\left(\omega_{\mathrm{r}}=230 \mathrm{rad} / \mathrm{s}, \mathrm{T}_{\mathrm{e}}=16.5 \mathrm{Nm}\right)\left[\mathrm{i}_{\mathrm{as}}-20 \mathrm{~A} / \mathrm{div}, \mathrm{v}_{\mathrm{as}}-150 / \mathrm{div}\right.$, $\mathrm{V}_{\mathrm{as}}=500 \mathrm{~V} / \mathrm{div}$ and $\left.\mathrm{t}-1.92 \mathrm{~ms} / \mathrm{div}\right]$.

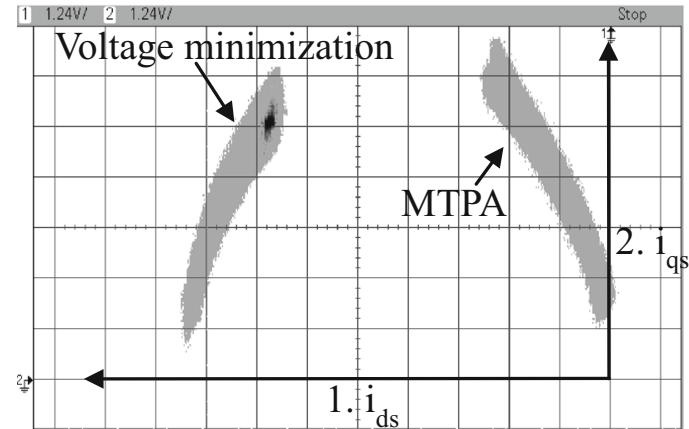

(a)

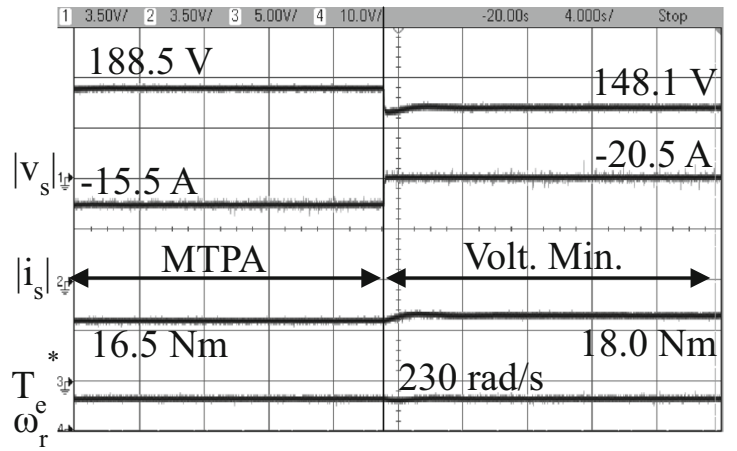

(b)

Figure 12. Experimental results of IPM motor showing comparison of voltage minimization and MTPA control. (a) The $i_{d s}-i_{q s}$ trajectory traced $\left[\mathrm{i}_{\mathrm{ds}}-3.72 \mathrm{~A} / \mathrm{div}\right.$, and $\left.\mathrm{i}_{\mathrm{qs}}-3.72 \mathrm{~A} / \mathrm{div}\right]$, and $(\mathbf{b})$ the magnitude of voltage and current at $\omega_{\mathrm{r}}=230 \mathrm{rad} / \mathrm{s}, \mathrm{T}_{\mathrm{e}}=16.5 \mathrm{Nm}\left[\mathrm{l} \mathrm{v}_{\mathrm{s}} \mid-\right.$ $105 \mathrm{~V} / \mathrm{div}, \mid \mathrm{i}_{\mathrm{s}} \mathrm{l}-10.5 \mathrm{~A} / \mathrm{div}, \mathrm{T}_{\mathrm{e}}-13.6 \mathrm{Nm} / \mathrm{div}, \omega_{\mathrm{r}}=400 \mathrm{rad} / \mathrm{s} / \mathrm{div}$ and $\left.\mathrm{t}-4 \mathrm{~s} / \mathrm{div}\right]$.

figures 11(c) and 11(d) for operation along MTPA control. The experimental results clearly demonstrate the minimum voltage operation along voltage minimization control technique. As seen in figure 10(c), the phase voltage $\mathrm{v}_{\mathrm{as}}$ is lower in comparison to phase voltage along MTPA control, as shown in figure $11(\mathrm{c})$. But the current magnitude is lower along MTPA control as compared to voltage minimization technique. $v_{\text {as }}$ and $i_{\text {as }}$ for motor operation under load, are shown in figures 10(d) and 11(d) for voltage minimization and MTPA control, respectively. It is clearly seen that the voltage minimization control operates at lower voltage and MTPA control operates at lower current. 
These results can be correlated to simulation results shown in figure 8 . Both, the PWM voltage $V_{a s}\left(3 V_{a s}=V_{a b}-\right.$ $\mathrm{V}_{\mathrm{ca}}$ ) measured at motor terminals and the fundamental phase voltage estimated using the reference wave of SPWM are shown. Here $\mathrm{v}_{\mathrm{as}}=0.5 \mathrm{~V}_{\mathrm{dc}} \mathrm{v}_{\mathrm{asc}}$, where $\mathrm{V}_{\mathrm{dc}}$ is the DC-link voltage and $\mathrm{v}_{\mathrm{asc}}$ is the reference signal of SPWM corresponding to phase A.

The $\mathrm{i}_{\mathrm{ds}}$ and $\mathrm{i}_{\mathrm{qs}}$ trajectories traced for operation along voltage minimization and MTPA control are shown in figure 12(a). These trajectories correspond to experiment results figures $10(\mathrm{~b})$ and 11(b). The trajectory traced along voltage minimization is the current limit locus and along MTPA control is the MTPA trajectory. These results can be correlated to simulation results shown in figures 6(f) and 7(f). Also, comparison of voltage magnitude and current magnitude for operation along voltage minimization and current minimization is shown in figure. 12(b). The IPM motor is operating at $\omega_{\mathrm{r}}=230 \mathrm{rad} / \mathrm{s}$ and is under load $\mathrm{T}_{\mathrm{e}}=16.5 \mathrm{Nm}$. It is clearly seen that the voltage magnitude is lower for operation along voltage minimization and current magnitude is lower for operation along MTPA.

The $\mathrm{V}_{\text {as }}$ phase voltage tapped from dsp using the reference voltage $\mathrm{v}_{\text {asc }}$ is slightly distorted. This distortion can be reduced by use of slower PI controller design. Although this would also result in a slower speed response.

\section{Concluding remarks}

Current minimization is the commonly used control technique adopted for control of IPM motors. Current minimization aims at minimizing the current vector per torque i.e., the copper losses. It fails to consider the core losses of the motor. Depending on the motor ratings, design and parameters, the ratio of copper to core losses vary. Thus, for motors having a greater proportion of core losses, it would be advantageous to operate along core loss minimization, rather than copper loss minimization. This is especially true for motors having low stator resistance, thus low copper losses. The core loss minimization control would mean voltage minimization i.e., torque per minimum voltage.

The trajectory of Maximum Torque Per Voltage (MTPV) is utilized only for deep-field weakening. The operation along MTPV right from zero-speed and zeroload is not looked into. This paper proposes voltage minimization control, where the operation is along voltage minimization trajectory, right from standstill. Since the MTPV trajectory falls outside the chosen IPM motor limits, the operation along current limit locus itself forms the voltage minimization trajectory as explained in the paper. The mathematical model of IPM motor for control along voltage minimization is established and the solution to the quartic equation involved is derived using Ferrari's method. The solution is utilized to develop a LUT for the experimental implementation of vector controlled IPM motor.

The voltage minimization control of IPM motor is experimentally demonstrated. Also, comparative analysis is done between voltage minimization and current minimization i.e., MTPA control. It is clear from the experimental results that the voltage minimization control offers lower operating voltage in comparison to MTPA control and therefore lower core losses. On the other hand, the current drawn is higher under voltage minimization and thus are the copper losses. Based on the motor parameters and design, the control technique can be chosen either to be voltage minimization or current minimization. An added advantage of voltage minimization is the simplicity of control, as the operation is always along the current limit locus irrespective of operation in field weakening.

\section{Appendix}

The motor parameters are: $\mathrm{L}_{\mathrm{d}}=3.2 \mathrm{mH}, \mathrm{L}_{\mathrm{q}}=8 \mathrm{mH}, \mathrm{r}_{\mathrm{s}-}$ $=0.244 \Omega, \lambda_{\mathrm{m}}=0.156 \mathrm{wb}, \mathrm{P}=8$. The rms current and voltage rating is taken as: $i_{\mathrm{s}}=15 \mathrm{~A}$ and $\mathrm{v}_{\mathrm{s}}=130 \mathrm{~V}$. Rated speed $\omega_{\mathrm{r}}=230 \mathrm{rad} / \mathrm{s}$ and rated torque $\mathrm{T}_{\mathrm{r}}=23 \mathrm{Nm}$ [Moog make].

PI controller gains (simulation): $\mathrm{K}_{\mathrm{pid}}=6.153, \mathrm{~K}_{\mathrm{iid}}$ $=469, \quad \mathrm{~K}_{\mathrm{piq}}=15.38, \quad \mathrm{~K}_{\mathrm{iiq}}=469, \quad \mathrm{~K}_{\mathrm{p} \omega}=1.659 \mathrm{e} 3$, $\mathrm{K}_{\mathrm{i} \omega}=1.5 \mathrm{e} 6$.

PI controller gains (experimental setup): $\mathrm{K}_{\text {pid }}=0.5$, $\mathrm{K}_{\mathrm{iid}}=50, \mathrm{~K}_{\text {piq }}=0.5, \mathrm{~K}_{\mathrm{iqq}}=50, \mathrm{~K}_{\mathrm{p} \omega}=0.05, \mathrm{~K}_{\mathrm{i} \omega}=0.15$.

\section{List of symbols}

$\mathrm{i}_{\mathrm{ds}}, \mathrm{i}_{\mathrm{qs}} \quad \mathrm{d}$-axis and $\mathrm{q}$-axis components of stator current $\mathrm{v}_{\mathrm{ds}}, \mathrm{v}_{\mathrm{qs}} \mathrm{d}$-axis and $\mathrm{q}$-axis components of stator voltage

$\lambda_{\mathrm{ds}}, \lambda_{\mathrm{qs}} \quad \mathrm{d}$-axis and q-axis stator flux

$\mathrm{r}_{\mathrm{s}} \quad$ stator resistance

$\lambda_{\mathrm{m}} \quad$ permanent magnet flux linkage per phase

$\omega_{\mathrm{e}} \quad$ rotor speed in electrical $\mathrm{rad} / \mathrm{s}$

$\omega_{\mathrm{r}} \quad$ rotor speed in mechanical $\mathrm{rad} / \mathrm{s}$

$\theta_{\mathrm{e}} \quad$ rotor position in electrical rad

$\mathrm{T}_{\mathrm{e}} \quad$ develop electrical torque

$\mathrm{L}_{\mathrm{d}} \mathrm{d}$-axis inductance

$\mathrm{L}_{\mathrm{q}} \quad \mathrm{q}$-axis inductance

$\rho \quad$ saliency ratio $\mathrm{L}_{\mathrm{q}} / \mathrm{L}_{\mathrm{d}}$

$\mathrm{K}_{\text {pid }}, \mathrm{K}_{\mathrm{iid}}$ proportional and integral gain for d-axis current PI controller

$\mathrm{K}_{\mathrm{piq}}, \mathrm{K}_{\mathrm{iiq}}$ proportional and integral gain for q-axis current PI controller

$\mathrm{K}_{\mathrm{p} \omega}, \mathrm{K}_{\mathrm{i} \omega}$ proportional and integral gain for speed PI controller

Subscript 'b' refers to base quantities and subscript ' $n$ ' refers to normalized quantities and ' $r$ ' indicates rated value. 


\section{References}

[1] Jahns T M, Kliman G B and Thomas Neumann W 1986 Interior permanent-magnet synchronous motors for adjustable-speed drive. IEEE Trans. Ind. Appl. 22(4): 738-747

[2] Jahns T M 1987 Flux-weakening regime operation of an interior permanent-magnet synchronous motor drive. IEEE Trans. Ind. Appl. 23(4): 681-689

[3] Morimoto S, Sanada M and Takeda Y 1994 Wide-speed operation of interior permanent magnet synchronous motors with high-performance current regulator. IEEE Trans. Ind. Appl. 30(4): 920-926

[4] Nguyen Q K, Petrich M and Roth-Stielow J 2014 Implementation of the MTPA and MTPV control with online parameter identification for a high speed IPMSM used as traction drive. In: Int. Conf. Power Elec. Hiroshima. 318-323

[5] Consoli A, Scelba G, Scarcella G and Cacciato M 2013 An effective energy-saving scalar control for industrial IPMSM drives. IEEE Trans. Ind. Elec. 60(9): 3658-3669

[6] Jung S-Y, Hong J and Nam K 2013 Current minimizing torque control of the IPMSM using Ferrari's method. IEEE Trans. Power Elec. 28(12): 5603-5617

[7] Bae B-H, Patel N, Schulz S and Sul S-K 2003 New field weakening technique for high saliency interior permanent magnet motor. In: Conf. Ind. Appl., Salt Lake City, UT, USA. 898-905

[8] Bolognani S, Petrella R, Prearo A and Sgarbossa L 2011 Automatic tracking of MTPA trajectory in IPM motor drives based on AC current injection. IEEE Trans. Ind. Appl. 47 (1): 105-114

[9] Takahashi I and Noguchi T 1986 A new quick-response and high-efficiency control strategy of an induction motor. IEEE Trans. Ind. Appl. 22(5): 820-827

[10] Zhong L, Rahman M F, Hu W Y and Lim K W 1997 Analysis of direct torque control in permanent magnet synchronous motor drives. IEEE Trans. Power Elec. 12(3): 528-536

[11] Rahman M F, Zhong L and Lim K W 1998 A direct torquecontrolled interior permanent magnet synchronous motor drive incorporating field weakening. IEEE Trans. Ind. Appl. 34(6): 1246-1253

[12] Tang L, Zhong L, Rahman M F and Hu Y 2004 A novel direct torque controlled interior permanent magnet synchronous machine drive with low ripple in flux and torque and fixed switching frequency. IEEE Trans Power Elec. 19(2): 346-354

[13] Haque M E, Limin Zhong and Rahman M F 2003 A sensorless initial rotor position estimation scheme for a direct torque controlled interior permanent magnet synchronous motor drive. IEEE Trans. Power Elec. 18(6): 1376-1383

[14] Wang B, Guo W, Wang Y and Wang Z 2008 A deadbeat direct torque control of surface permanent magnet synchronous machines using space vector modulation. In: Int. Conf. Electrical Machines and Systems, Wuhan. 1086-1088

[15] Daghigh A, Sharifian M B B and Farasat M 2010 A modified direct torque control of IPM synchronous machine drive with constant switching frequency and low ripple in torque. In: Conf. Electrical Engineering, Iran. 778-783

[16] Zhang Y, Zhu J, Xu W and Guo Y 2011 A simple method to reduce torque ripple in direct torque-controlled permanent- magnet synchronous motor by using vectors with variable amplitude and angle. IEEE Trans. Ind. Elec. 58(7): 2848-2859

[17] Chikh K, Khafallah K, Saad A, Yousfi D and Chaikhy H 2012 A novel fixed-switching-frequency DTC for PMSM drive with low torque and flux ripple based on Sinusoidal Pulse With Modulation and predictive controller. In: Int. Conf. Multimedia Computing and Systems, Tangier. 1069-1075

[18] Zhang Y, Yang H and Li Z 2013 A simple SVM-based deadbeat direct torque control of induction motor drives. In: Int. Conf. Electrical Machines and Systems, Busan. 2201-2206

[19] Foo G H B and Zhang X 2016 Constant switching frequency based direct torque control of interior permanent magnet synchronous motors with reduced ripples and fast torque dynamics. IEEE Trans. Power Elec. 31(9): 6485-6493

[20] Inoue T, Inoue Y, Morimoto S and Sanada M 2015 Mathematical model for MTPA control of permanent-magnet synchronous motor in stator flux linkage synchronous frame. IEEE Trans. Ind. Appl. 51(5): 3620-3628

[21] Inoue T, Inoue Y, Morimoto S and Sanada M 2016 Maximum torque per ampere control of a direct torque controlled PMSM in a stator flux linkage synchronous frame. IEEE Trans. Ind. Appl. 50(3): 2360-2367

[22] Ogasawara S and Akagi H 1998 Implementation and position control performance of a position-sensorless IPM motor drive system based on magnetic saliency. IEEE Trans. Ind. Appl. 34(4): 806-812

[23] Lin C K, Liu T H and Lo C H 2008 Sensorless interior permanent magnet synchronous motor drive system with a wide adjustable speed range. IET Electric Power Appl. 3(2): 133-146

[24] Chen J L, Liu T H and Chen C L 2010 Design and implementation of a novel high-performance sensorless control system for interior permanent magnet synchronous motors. IET Electric Power Appl. 4(4): 226-240

[25] Park N C and Kim S H 2014 Simple sensorless algorithm for interior permanent magnet synchronous motors based on high-frequency voltage injection method. IET Electric Power Appl. 8(2): 68-75

[26] Bolognani S, Tubiana L and Zigliotto M 2003 EKF-based sensorless IPM synchronous motor drive for flux-weakening applications. IEEE Trans. Ind. Appl. 39(3): 768-775

[27] De Angelo, Bossio C H, Solsona G R, Garcia J A and Valla M I 2005 Sensorless speed control of permanent-magnet motors with nonsinusoidal EMF waveform. IEE Proceedings - Electric Power Appl. 152(5): 1119-1126

[28] Al-nabi E, Wu B, Zargari N R and Sood V 2013 Sensorless control of CSC-fed IPM machine for zero- and low-speed operations using pulsating HFI method. IEEE Trans. Ind. Elec. 60(5): 1711-1723

[29] Xiao D and Rahman M F 2013 Sensorless direct torque and flux controlled IPM synchronous machine fed by matrix converter over a wide speed range. IEEE Trans. Ind. Informatics 9(4): 1855-1867

[30] Lim M S, Chai S H and Hong J P 2014 Design and iron loss analysis of sensorless-controlled interior permanent magnet synchronous motors with concentrated winding. IET Electric Power Appl. 8(9): 349-356 
[31] Tseng S K, Liu T H and Chen J L Implementation of a sensorless interior permanent magnet synchronous drive based on current deviations of pulse-width modulation switching. IET Electric Power Appl. 9(2): 95-106

[32] Ekanayake S, Dutta R, Rahman M F and Xiao D 2015 Deep flux weakening control of a segmented interior permanent magnet synchronous motor with maximum torque per voltage control. In: IEEE Conf. Ind. Elec. 004802-004807
[33] Lin P Y, Lee W T, Chen S W, Hwang J C and Lai Y S 2014 Infinite speed drives control with MTPA and MTPV for interior permanent magnet synchronous motor. In: IEEE Conf. Ind. Elec. 668-674

[34] Pellegrino G, Armando E and Guglielmi P 2012 Direct-flux vector control of IPM motor drives in the maximum torque per voltage speed range. IEEE Trans. Ind. Elec. 59(10): 3780-3788 